\title{
PEMODELAN JARINGAN SYARAF TIRUAN DENGAN CASCADE FORWARD BACKPROPAGATION PADA KURS RUPIAH TERHADAP DOLAR AMERIKA SERIKAT
}

\author{
Ekky Rosita Singgih Wigati ${ }^{1}$, Budi Warsito ${ }^{2}$, Rita Rahmawati ${ }^{3}$ \\ 1,2,3 Departemen Statistika, Fakultas Sains dan Matematika, Universitas Diponegoro \\ e-mail : budiwrst2@gmail.com
}

\begin{abstract}
Neural Network Modeling (NN) is an information-processing system that has characteristics in common with human brain. Cascade Forward Neural Network (CFNN) is an artificial neural network that its architecture similar to Feed Forward Neural Network (FFNN), but there is also a direct connection from input layer and output layer. In this study, we apply CFNN in time series field. The data used isexchange rate of rupiah against US dollar period of January $1^{\text {st }}, 2015$ until December $31^{\text {st }}, 2017$. The best model was built from 1 unit input layer with input $\mathrm{Z}_{\mathrm{t}-1}, 4$ neurons in the hidden layer, and 1 unit output layer. The activation function used are the binary sigmoid in the hidden layer and linear in the output layer. The model produces MAPE of training data equal to $0.2995 \%$ and MAPE of testing data equal to $0.1504 \%$. After obtaining the best model, the data is foreseen for January 2018 and produce MAPE equal to $0.9801 \%$.
\end{abstract}

Keywords: artificial neural network, cascade forward, exchange rate, MAPE

\section{PENDAHULUAN}

Jaringan syaraf tiruan (JST) atau yang biasa disebut Artificial Neural Network (ANN) merupakan sistem pemrosesan informasi yang memiliki karakteristik mirip dengan jaringan syaraf pada makhluk hidup (Fausett, 1994). Prinsip dari pemodelan Neural Network dikembangkan dari karakteristik dan cara kerja otak manusia, dimana dalam memroses informasi otak manusia terdiri dari sejumlah neuron yang melakukan tugas sederhana. Adanya keterhubungan antar neuron menyebabkan otak manusia dapat melakukan fungsi pemrosesan yang sangat kompleks. Pemrosesan informasi dapat dilakukan setelah melalui proses pembelajaran sebelumnya. Pada jaringan syaraf manusia, pemrosesan informasi bersifat adaptif yang artinya hubungan antar neuron terjadi secara dinamis, kekuatan hubungan antar neuron dapat berubah dari waktu ke waktu, serta selalu mempunyai kemampuan untuk mempelajari informasi-informasi baru (Warsito, 2009).

Arsitektur jaringan syaraf tiruan yang banyak digunakan dalam penelitian saat ini yaitu Feed Forward Neural Network (FFNN). Dalam FFNN, input layer dihubungkan dengan hidden layer lalu hidden layer dihubungkan dengan output layer. Tidak terdapat hubungan langsung antara input layer dengan output layer. Hal inilah yang mendasari peneliti untuk memodelkan kurs rupiah terhadap dolar menggunakan Cascade Forward Neural Network (CFNN) yang hampir serupa dengan FFNN, tetapi juga terdapat hubungan langsung antara input layer dengan outpu layer.

Dalam perkembangan saat ini, pemodelan JST banyak diterapkan pada berbagai aplikasi. Salah satu penerapan dalam masalah statistika adalah pada bidang time series. Peramalan dengan metode time series yang umum digunakan dalam penelitian adalah Autoregressive Integrated Moving Average (ARIMA). Metode ARIMA memiliki asumsiasumsi yang harus dipenuhi. Akan tetapi, dalam praktiknya pada data real tidak semua asumsi dapat dengan mudah terpenuhi.

Penelitian berkaitan dengan pemodelan jaringan syaraf tiruan sudah pernah dilakukan sebelumnya. Penelitian tersebut berjudul "Pemodelan Jaringan Syaraf Tiruan dengan Algoritma One Step Secant Backpropagation dalam Return Kurs Rupiah Terhadap Dolar Amerika Serikat" (Najwa, 2017). Penelitian tersebut membuat pemodelan jaringan 
syaraf tiruan dengan arsitektur Feed Forward Neural Network (FFNN). Hal inilah yang mendorong penulis memodelkan jaringan syaraf tiruan dengan arsitektur Cascade Forward Backpropagation.

\section{TINJAUANPUSTAKA}

\subsection{Kurs}

Nilai tukar mata uang atau yang sering disebut dengan kurs adalah harga satu unit mata uang asing dalam mata uang domestik atau dapat juga dikatakan harga mata uang domestik terhadap mata uang asing (Suseno, 2004).

\subsection{Time Series}

Time series atau runtun waktu adalah suatu rangkaian variabel yang diamati pada interval waktu ruang yang sama ditunjukkan sebagai sebuah deret berkala (Makridakis dan Wheelwright, 1999).

\subsubsection{Fungsi Autokorelasi/ Autocorrelation Function (ACF)}

Menurut Wei (2006), suatu runtun waktu yang stasioner terdapat nilai mean $\mathrm{E}\left(\mathrm{X}_{\mathrm{t}}\right)=\mu$ dan varian $\operatorname{Var}\left(\mathrm{X}_{\mathrm{t}}\right)=\sigma^{2}$ yang konstan serta $\operatorname{Cov}\left(\mathrm{X}_{\mathrm{t}}, \mathrm{X}_{\mathrm{t}+\mathrm{k}}\right)$ dari sini dapat ditulis kovarian antara $X_{t}$ dan $X_{t+k}$ adalah sebagai berikut :

$$
\gamma_{k}=\operatorname{Cov}\left(X_{t}, X_{t+k}\right)=E\left(X_{t}-\mu\right)\left(X_{t+k}-\mu\right) \text {, }
$$

dan korelasi antara $X_{t}$ dan $X_{t+k}$ adalah :

dengan $\operatorname{Var}\left(X_{t}\right)=\operatorname{Var}\left(X_{t+k}\right)=\gamma_{0}$.

$$
\rho_{k}=\frac{\operatorname{Cov}\left(X_{t}, X_{t+k}\right)}{\sqrt{\operatorname{Var}\left(X_{t}\right)} \sqrt{\operatorname{Var}\left(X_{t+k}\right)}}=\frac{\gamma_{k}}{\gamma_{0}}
$$

\subsubsection{Fungsi Autokorelasi Parsial/Partial Autocorrelation Function (PACF)}

Menurut Makridakis dan Wheelwright (1999) autokorelasi parsial digunakan untuk mengukur tingkat keeratan antara $Z_{t}$ dan $Z_{t+k}$, apabila pengaruh dari lag waktu $1,2,3, \ldots \mathrm{k}-1$ dianggap terpisah. Fungsi autokorelasi parsial dirumuskan sebagai berikut (Wei, 2006):

$$
\rho_{k}=\frac{\operatorname{Cov}\left[\left(Z_{t}-\hat{Z}_{t}\right),\left(Z_{t+k}-\hat{Z}_{t+k}\right)\right]}{\sqrt{\operatorname{Var}\left(Z_{t}-\hat{Z}_{t}\right)} \sqrt{\operatorname{Var}\left(Z_{t+k}-\hat{Z}_{t+k}\right)}}
$$

Dalam pengamatan time series, sampel PACF dinotasikan dengan $\emptyset_{k k}$ dengan perhitungan (Wei, 2006):

$$
\phi_{k k}=\frac{\left|\begin{array}{cccccc}
1 & \rho_{1} & \rho_{2} & \cdots & \rho_{k-2} & \rho 1 \\
\rho_{1} & 1 & \rho_{1} & \cdots & \rho_{k-3} & \rho_{2} \\
\vdots & \vdots & \vdots & \cdots & \vdots & \vdots \\
\rho_{k-1} & \rho_{k-2} & \rho_{k-3} & \cdots & \rho_{1} & \rho_{k}
\end{array}\right|}{\left|\begin{array}{cccccc}
1 & \rho_{1} & \rho_{2} & \cdots & \rho_{k-2} & \rho_{k-1} \\
\rho_{1} & 1 & \rho_{1} & \cdots & \rho_{k-3} & \rho_{k-2} \\
\vdots & \vdots & \vdots & \cdots & \vdots & \vdots \\
\rho_{k-1} & \rho_{k-2} & \rho_{k-3} & \cdots & \rho_{1} & 1
\end{array}\right|}
$$




\subsection{Jaringan Syaraf Tiruan}

Jaringan syaraf adalah merupakan salah satu representasi buatan dari otak manusia yang selalu mencoba untuk mensimulasikan proses pembelajaran pada otak manusia tersebut (Kusumadewi, 2004).

\subsubsection{Arsitektur Jaringan}

Menurut Warsito (2009), neuron-neuron dalam Neural network tersusun dalam bentuk lapisan-lapisan (layer) dan memiliki pola keterhubungan baik dalam satu lapisan maupun antar lapisan. Susunan dari neuron-neuron dalam lapisan dan pola keterhubungan antar lapisan disebut sebagai arsitektur jaringan.

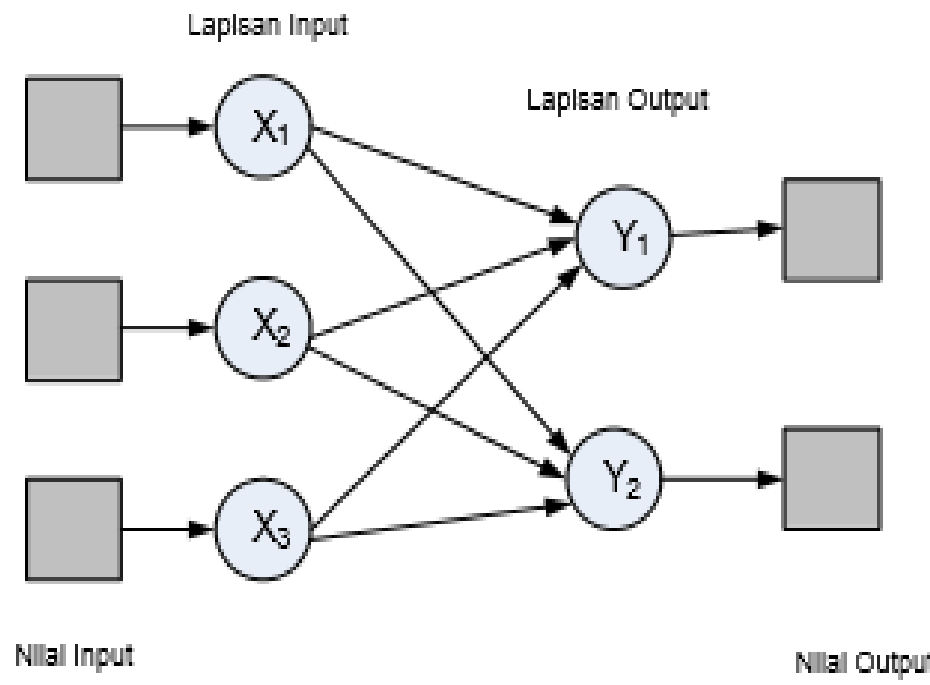

Gambar 1. Jaringan Lapisan Tunggal (Single Layer Network)

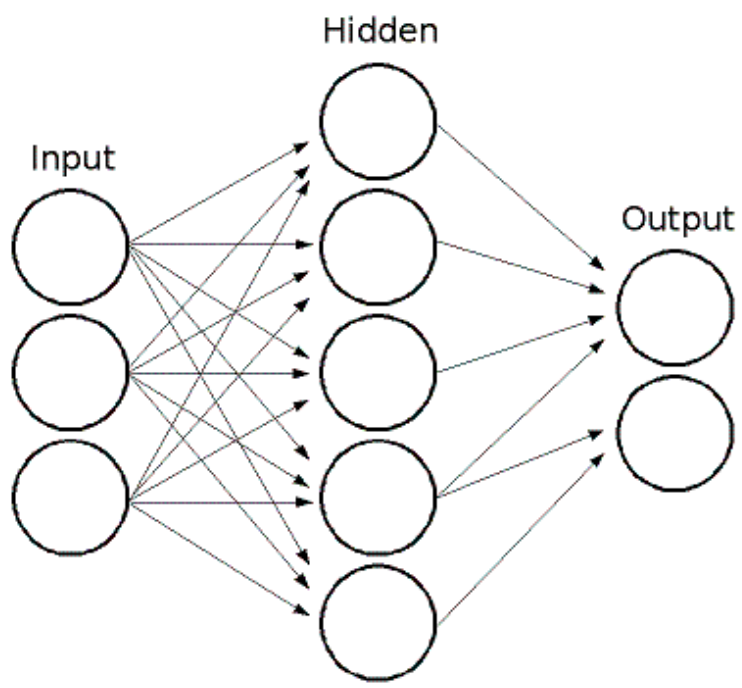

Gambar 2. Jaringan Lapisan Jamak (Multi Layer Network)

\subsubsection{Unit Bias}

Menurut Siang (2005), dalam jaringan syaraf tiruan sering kali ditambahkan sebuah unit input yang nilainya selalu bernilai satu, yang disebut dengan unit bias. Bias dapat dipandang sebagai sebuah input yang nilainya satu. Jika melibatkan bias, maka output unit penjumlah adalah sebagai berikut: 


\subsubsection{Fungsi Aktivasi}

$$
\text { net }=w_{0}+\sum_{i=1}^{n} x_{i} w_{i}
$$

Menurut Siang (2005) dalam jaringan syaraf tiruan, fungsi aktivasi dipakai untuk menentukan output suatu neuron. Argumen fungsi aktivasi adalah net input (kombinasi linier input dan bobotnya). Jika net $=\sum x_{i} w_{i}$, maka fungsi aktivasinya adalahf(net) $=$ $\mathrm{f}\left(\sum x_{i} w_{i}\right)$.

\subsection{Backpropagation}

\subsubsection{Konsep Dasar}

Menurut Kusumadewi (2004) backpropagation merupakan algoritma pembelajaran yang terawasi dan biasanya digunakan oleh perceptron dengan banyak layer untuk mengubah bobot-bobot yang terhubung dengan neuron-neuron yang ada pada hidden layer. Algoritma backpropagation menggunakan output untuk mengubah nilai bobot-bobotnya dalam arah mundur (backward). Untuk mendapatkan error ini, tahap perambatan maju (forward propagation) harus dikerjakan terlebih dahulu.

\subsubsection{Pelatihan Standar Backpropagation}

Menurut Siang (2005) pelatihan backpropagation meliputi tiga fase. Pertama adalah fase maju. Pola input dihitung maju mulai dari input layer hingga output layer menggunakan fungsi aktivasi yang ditentukan. Fase kedua adalah fase mundur. Selisih antara ouput jaringan dengan target yang diinginkan merupakan kesalahan yang terjadi. Kesalahan tersebut dipropagasikan mundur, dimulai dari garis yang berhubungan langsung dengan unit-unit di output layer. Fase ketiga adalah modifikasi bobot untuk menurunkan kesalahan yang terjadi.

\subsection{Cascade Forward Neural Network (CFNN)}

Arsitektur jaringan Cascade Forward Neural Network (CFNN) hampir serupa dengan arsitektur jaringan Feed Forward Neural Network (FFNN). Pada FFNN hubungan input dan output bukan merupakan hubungan langsung, sedangkan pada CFNN terdapat hubungan langsung antara input dan output.

Input layer Hidden layer Output layer

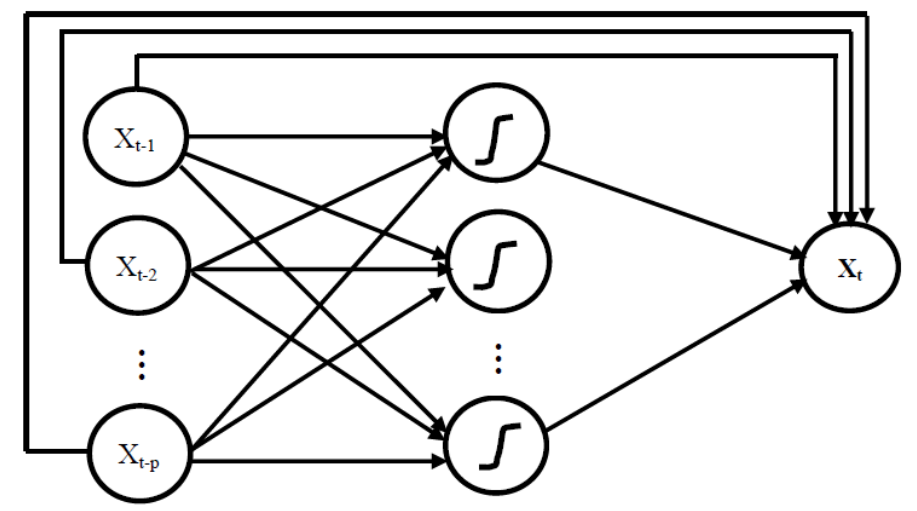

Gambar 3. Arsitektur Cascade Forward Neural network

Bentuk persamaan dari model CFNN satu unit output layer dapat ditulis sebagai berikut : 


$$
y=\sum_{i=1}^{I} f^{i} u_{i k} x_{i}+f^{0}\left(w_{o k}+\sum_{j=1}^{J} w_{j k} f^{j}\left(v_{o j}+\sum_{j=1}^{J} \sum_{i=1}^{I} v_{i j} x_{i}\right)\right)
$$

\subsection{Kriteria Pemilihan Model Terbaik}

Dalam penelitian tugas akhir ini, pemilihan model terbaik dilihat berdasarkan nilai Mean Absolute PercentageError (MAPE). MAPE merupakan nilai tengah kesalahan presentase absolute, jadi pada MAPE nilai positif atau negatif error tidak dihiraukan. Nilai MAPE dapat dihitung menggunakan rumus:

$$
M A P E=\frac{1}{n} \sum_{t=1}^{n} \frac{\left|X_{t}-\hat{X}_{t}\right|}{X_{t}} x 100 \%
$$

Semakin kecil nilai yang dihasilkan oleh alat ukur tersebut, maka metode peramalan yang digunakan akan semakin baik. Suatu model mempunyai kinerja sangat bagus jika nilai MAPE berada di bawah $10 \%$ dan mempunyai kinerja bagus jika nilai MAPE berada di antara 10\% dan 20\% (Zainun dan Majid, 2003).

\section{METODOLOGI PENELITIAN}

\subsection{Jenis dan Sumber Data}

Data yang digunakan dalam penelitian tugas akhir ini merupakan data sekunder yang bersumber dari website Bank Indonesia (www.bi.go.id). Data tersebut merupakan data pergerakan kurs rupiah terhadap dolar Amerika pada periode 1 Januari 2015 sampai dengan periode 31 Desember 2017 dengan menggunakan hari aktif.

\subsection{Variabel Penelitian}

Variabel yang digunakan pada penelitian tugas akhir ini adalah data kurs rupiah terhadap dolar Amerika pada periode 1 Januari 2015 sampai dengan periode 31 Desember 2017 dengan menggunakan hari aktif sebanyak 734.

\subsection{Tahapan Pengolahan Data}

Langkah-langkah yang ditempuh untuk mencapai tujuan penelitian ini adalah sebagai berikut :

1. Menyiapkan data kurs rupiah terhadap dolar Amerika Serikat.

2. Menentukan nilai input berdasarkan plot PACF (Partial Auto Correlation Function).

3. Melakukan pembagian data menjadi 2, yaitu data training dan data testing.

4. Memasukkan nilai input dan nilai output pada jaringan syaraf tiruan.

5. Menentukan jumlah neuron hidden layer.

6. Menentukan bobot awal.

7. Melakukan inisialisasi parameter jaringan syaraf tiruan (max epoch, goal).

8. Melakukan proses training.

9. Menentukan apakah MSE sudah lebih kecil dari nilai MSE yang ditetapkan.

a. Jika iya, maka dilanjutkan dengan proses selanjutnya.

b. Jika tidak, maka kembali pada proses inisialisasi parameter jaringan syaraf tiruan.

10. Menentukan bobot akhir.

11. Melakukan proses testing.

12. Melakukan peramalan (forecasting) untuk beberapa periode ke depan. 


\section{HASIL DAN PEMBAHASAN}

\subsection{Menentukan Input}

Penentuan input jaringan dilakukan dengan menggunakan plot PACF. Hal ini dikarenakan hubungan antara data yang akan dicari dipengaruhi oleh data periode sebelumnya. Input jaringan yang digunakan adalah lag-lag yang signifikan pada plot PACF dilihat dari garis yang melewati selang kepercayaan (garis putus-putus).

Berdasarkan Plot PACF, garis yang secara signifikan melewati selang kepercayaan adalah lag 1. Hal ini menunjukkan bahwa diperoleh satu variabel yang akan dijadikan komponen input yaitu lag 1. Dapat dikatakan bahwa jaringan terdiri atas $x_{t}$ dipengaruhi oleh $x_{t-1}$, sehingga data yang digunakan untuk input jaringan sejumlah 733 .

\subsection{Pembagian data dan Pennetuan Jumlah Neuron pada Lapisan tersmebunyi}

Data pada pemodelan jaringan syaraf tiruan dengan Cascade Forward Backpropagation ini dibagi menjadi data training dan data testing dengan dicobakan beberapa perbandingan. Didapatkan perbandingan terbaik $90 \%$ data training dan $10 \%$ data testing dengan neuron pada hidden layer sebanyak 3 dengan MAPE sebesar 0,2995\%.

\subsection{Fungsi Aktivasi}

Fungsi aktivasi yang digunakan dalam jaringan ini ada dua yaitu fungsi Sigmoid biner (logistic sigmoid) dan fungsi linear (identitas).

\subsection{Normalisasi Data}

Sebelum dilakukan pelatihan terhadap jaringan syaraf, diperlukan penskalaan pada input data dan target sehingga data masuk pada range tertentu. Hal ini dimaksudkan agar data yang diproses sesuai dengan fungsi aktivasi yang digunakan. Proses ini disebut dengan pre-processing. Kemudian setelah proses pelatihan selesai dilakukan, data dikembalikan ke bentuk aslinya disebut dengan post-processing(Warsito, 2009). Proses pre-processing pada jaringan syaraf tiruan ini dilakukan dengan normalisasi data. Rumus yang digunakan yaitu:

$$
x^{\prime}=\frac{x-\min (x)}{\max (x)-\min (x)}
$$

\subsection{Membangun Jaringan Casacade Forward Neural Network}

Membangun jaringan syaraf tiruan dengan Cascade forward Neural Network pada MATLAB digunakan perintah newc $f$, sebagai berikut: net=newcf (pn,tn, [3 1], \{'logsig' 'purelin'\},'traincgf')

Perintah di atas menunjukkan bahwa terdapat 3 neuron pada hidden layer dan 1 neuron pada output layer. Fungsi aktivasi yang digunakan pada hidden layer adalah sigmoid biner dan pada output layer adalah fungsi linear (identitas). Algoritma pelatihan yang digunakan adalah Conjugate gradient backpropagation.

\subsection{Menentukan Bobot Awal}

Hasil bobot awal yang diperoleh dari pelatihan jaringan dengan MATLAB dapat dilihat pada Tabel 1 dan Tabel 2.

Tabel 1. Bobot awal dari input ke hidden layer

\begin{tabular}{|c|c|c|c|}
\hline & $\mathrm{Z}_{1}$ & $\mathrm{Z}_{2}$ & $\mathrm{Z}_{3}$ \\
\hline $\mathrm{X}_{\mathrm{t}-1}$ & $-8,4$ & $-8,4$ & $-8,4$ \\
\hline 1 & 8,4 & 0 & $-8,4$ \\
\hline
\end{tabular}


Tabel 2. Bobot awal dari input dan hidden layer ke output

\begin{tabular}{|c|c|c|c|c|c|}
\hline & $\mathrm{X}_{\mathrm{t}-1}$ & 1 & $\mathrm{Z}_{1}$ & $\mathrm{Z}_{2}$ & $\mathrm{Z}_{3}$ \\
\hline $\mathrm{y}$ & $-0,4240$ & 0,4690 & $-0,7006$ & 0,2676 & $-0,7726$ \\
\hline
\end{tabular}

\subsection{Proses Training}

Proses training jaringan dilakukan dengan algoritma conjugate gradientbackpropagation. Iterasi berhenti pada epoch ke 27 dengan nilai MAPE sebesar $0,2995 \%$.

\subsection{Menentukan Bobot Akhir}

Hasil bobot akhir yang diperoleh dari pelatihan jaringan dengan MATLAB sebagai berikut:

Tabel 3. Bobot akhir dari input ke hidden layer

\begin{tabular}{|c|c|c|c|}
\hline & $\mathrm{Z}_{1}$ & $\mathrm{Z}_{2}$ & $\mathrm{Z}_{3}$ \\
\hline $\mathrm{X}_{\mathrm{t}-1}$ & $-8,3546$ & $-8,3818$ & $-8,2873$ \\
\hline 1 & 8,4430 & $-0,0129$ & $-8,5009$ \\
\hline
\end{tabular}

Tabel 4. Bobot akhir dari input dan hidden layer ke output

\begin{tabular}{|c|c|c|c|c|c|}
\hline & $\mathrm{X}_{\mathrm{t}-1}$ & 1 & $\mathrm{Z}_{1}$ & $\mathrm{Z}_{2}$ & $\mathrm{Z}_{3}$ \\
\hline $\mathrm{y}$ & $-0,2558$ & 0,4549 & $-0,5854$ & 0,2900 & $-0,5907$ \\
\hline
\end{tabular}

\subsection{Proses Testing}

Proses testing telah memberikan hasil prediksi cukup akurat yang ditunjukkan oleh kedekatan target $\left(\right.$ data asli $\left.=\mathrm{X}_{\mathrm{t}}\right)$. Proses testing menghasilkan MAPE sebesar 0,1504\%.

\subsection{Penentuan Model}

Arsitektur model Cascade Forward Backpropagation terbaik dibangun dari 3 neuron hidden layer dengan 1 input layer yaitu $\mathrm{x}_{\mathrm{t}-1}$ dan 1 output layer.

dengan:

$$
y=u_{11} x_{1}+w_{o 1}+\sum_{j=1}^{3} w_{j 1}\left(\frac{1}{1+e^{-\left(v_{o j}+\sum_{j=1}^{3} v_{1 j} x_{1}\right)}}\right)
$$

$$
\begin{aligned}
& u_{11}=-0,2558, w_{o 1}=0,4549, w_{11}=-0,5854, w_{21}=0,2900, w_{31}=-0,5907 \\
& v_{o 1}=8,4430, v_{o 2}=-0,0129, v_{o 3}=-8,5009 \\
& v_{11}=-8,3546, v_{12}=-8,3818, v_{13}=-8,2873
\end{aligned}
$$

\subsection{Peramalan}

Peramalan kurs rupiah terhadap dolar Amerika dengan menggunakan model terbaik pada periode 2 Januari 2018 adalah sebesar Rp. 13.296. Dengan proses yang sama didapatkan peramalan kurs rupiah terhadap dolar Amerika untuk bulan Januari 2018 pada Tabel 6.

Tabel 6. Hasil Peramalan Kurs Rupiah terhadap Dolar Amerika Serikat bulan Januari 2018

\begin{tabular}{|c|c|c|r|}
\hline Tanggal & Forecast & Aktual & Error \\
\hline $02 / 01 / 2018$ & 13296 & 13610 & 314 \\
\hline $03 / 01 / 2018$ & 13329 & 13565 & 236 \\
\hline $04 / 01 / 2018$ & 13295 & 13541 & 246 \\
\hline $05 / 01 / 2018$ & 13289 & 13472 & 183 \\
\hline $08 / 01 / 2018$ & 13296 & 13464 & 168 \\
\hline
\end{tabular}

\begin{tabular}{|r|r|r|r|}
\hline $09 / 01 / 2018$ & 13298 & 13495 & 197 \\
\hline $10 / 01 / 2018$ & 13291 & 13516 & 225 \\
\hline $11 / 01 / 2018$ & 13288 & 13494 & 206 \\
\hline $12 / 01 / 2018$ & 13291 & 13429 & 138 \\
\hline $15 / 01 / 2018$ & 13311 & 13397 & 86 \\
\hline $16 / 01 / 2018$ & 13327 & 13400 & 73 \\
\hline
\end{tabular}




\begin{tabular}{|c|c|c|r|}
\hline Tanggal & Forecast & Aktual & Error \\
\hline $17 / 01 / 2018$ & 13326 & 13390 & 64 \\
\hline $18 / 01 / 2018$ & 13332 & 13432 & 100 \\
\hline $19 / 01 / 2018$ & 13309 & 13398 & 89 \\
\hline $22 / 01 / 2018$ & 13327 & 13401 & 74 \\
\hline $23 / 01 / 2018$ & 13325 & 13385 & 60 \\
\hline
\end{tabular}

\begin{tabular}{|l|l|l|r|}
\hline $24 / 01 / 2018$ & 13336 & 13388 & 52 \\
\hline $25 / 01 / 2018$ & 13334 & 13356 & 22 \\
\hline $26 / 01 / 2018$ & 13359 & 13370 & 11 \\
\hline $29 / 01 / 2018$ & 13348 & 13394 & 46 \\
\hline $30 / 01 / 2018$ & 13329 & 13465 & 136 \\
\hline $31 / 01 / 2018$ & 13298 & 13480 & 182 \\
\hline
\end{tabular}

$$
\begin{gathered}
\text { MAPE }=\frac{1}{n} \sum_{t=1}^{n} \frac{\left|X_{t}-\hat{X}_{t}\right|}{X_{t}} \times 100 \% \\
M A P E=\frac{1}{22}\left(\frac{314}{13610}+\frac{236}{13565}+\cdots+\frac{182}{13480}\right) 100 \%=0,9801 \%
\end{gathered}
$$

Berdasarkan Tabel 6, diperoleh MAPE sebesar 0,9801\%. Nilai MAPE yang didapatkan kurang dari $10 \%$, maka dapat dikatakan keakuratan hasil peramalan sangat baik.

\section{PENUTUP}

\subsection{Kesimpulan}

Berdasarkan pembahasan mengenai pembentukan model jaringan syaraf tiruan dengan cascade forward backpropagation pada kurs rupiah terhadap dolar Amerika Serikat, maka dapat disimpulkan sebagai berikut:

1. Arsitektur model terbaik jaringan syaraf tiruan dengan Cascade forward Backpropagation dibangun dari 1 neuron lapisan input yaitu $\mathrm{x}_{\mathrm{t}-1}, \quad 3$ neuron lapisan tersembunyi, dan 1 neuron lapisan output. Fungsi aktivasi yang digunakan yaitu sigmoid biner pada lapisan tersembunyi dan linear pada lapisan output, dengan persamaan model sebagai berikut:

$$
y=u_{11} x_{1}+w_{o 1}+\sum_{j=1}^{3} w_{j 1}\left(\frac{1}{1+e^{-\left(v_{o j}+\sum_{j=1}^{3} v_{1 j} x_{1}\right)}}\right)
$$

Model tersebut menghasilkan MAPE trainingsebesar 0,2995\% dan MAPE testing sebesar 0,1504\% yang mana kedua nilai MAPE kurang dari $10 \%$ sehingga keakuratan model dikatakan sangat baik.

2. Peramalan untuk kurs rupiah terhadap dolar Amerika Serikat pada bulan Januari 2018 dengan model terbaik memberikan akurasi yang baik dengan MAPE sebesar $0,9801 \%$.

\subsection{Saran}

Model jaringan syaraf tiruan dengan Cascade Forward dapat dikembangkan dengan menggunakan berbagai macam algoritma pelatihan lainnya diantaranya Steepest Descent, BFGS, Gradient Descent, ataupun yang lainnya. Penambahan metode pada inisialisasi bobot awal juga dapat dilakukan.

\section{DAFTAR PUSTAKA}

Fausett, L. (1994). Fundamentals of Neural Networks; architectures,algorithms and applications. Englewoods Cliffs, New Jersey: Prentice-Hall Inc.

Kusumadewi, S. (2004). Membangun Jaringan Syaraf Tiruan Menggunakan MATLAB \& Excel Link. Yogyakarta: Graha Ilmu.

Makridakis, S., \& Wheelwright, S. C. (1999). Metode dan Aplikasi Peramalan. Jakarta: Erlangga. 
Najwa, M. (2017). Pemodelan Jaringan Syaraf Tiruan dengan Algoritma One Step Secant Beckpropagation dalam Return Kurs Rupiah terhadap Dolar Amerika Serikat. Gaussian, Vol 6, 61-70.

Siang, J. (2005). Jaringan Syaraf Tiruan dan Pemrogramannya Menggunakan Matlab . Yogyakarta: ANDI.

Suseno, I. S. (2004). Sistem dan Kebijakan Nilai Tukar. Jakarta: Pusat Pendidikan dan Studi Kebanksentralan (PPSK) Bank Indonesia.

Warsito, B. (2009). Kapita Selekta Statistika Neural Network. Semarang: BP Undip Seamarang.

Wei, W. (2006). Time Analysis Univariate and Multivariate Methods, 2nd Edition. USA: Addison Wesley Publishing Company, Inc.

Zainun, N., \& Majid, M. (2003). Low Cost House Demand Predictor. Universitas Teknologi Malaysia.

.Kamus Besar Bahasa Indonesia. [Online]. Tersedia di kbbi.kemdikbud.go.id/entri/kurs. Diakses 10 januari 2018 